\title{
The Use of Online Authentic Reading Materials In Online Reading Class
}

\author{
Fifi Nur Ulwiyah, fifi.18021@mhs.unesa.ac.id, UNESA, Surabaya, Indonesia \\ Ahmad Munir, ahmadmunirunesa@ac.id, UNESA, Surabaya, Indonesia \\ Slamet Setiawan, slametsetiawan@unesa.ac.id, UNESA, Surabaya, Indonesia
}

\begin{abstract}
In Indonesia, education is considered the large-scale power that must be compelled in the continuity of teaching activities through online learning during the COVID-19 pandemic. That is why it inspires the teachers to choose suitable material to fulfill students' needs and interests in teaching language. The appropriateness and well-chosen authentic materials in the context of reading have to cover meaningful content in which those are relevant. Thus, this study attempted to investigate those authenticities used and the teachers' challenges in implementing authentic online reading materials in the online reading classes of higher education. The study used a qualitative approach. The subjects were three EFL teachers of higher education that taught General English and English for Specific Purposes at the freshmen level during two semesters. The data collection techniques used were observation and interview. In analyzing the data, this study used Ary et al.'s (2010) theory: familiarizing and organizing; coding and reduction; interpreting and representing. The findings revealed that the term of authenticities was pivotal to being involved in the materials since the English language was taught as a foreign language. The authentic materials could be its prevalence by measuring each authenticity based on three areas of SLA (Second Language Acquisition), language pedagogy, and ICT (Information and Communication Technology). It could establish authenticity in the language learning design materials, especially learning the English language. Moreover, the challenge included the materials, students' interests, classroom activities, and classroom interaction among teachers and the students.
\end{abstract}

Keywords: Online authentic reading materials, online ELT, authenticity

\section{INTRODUCTION}

In 2020, the emergence of COVID-19 had a significant impact on nearly every aspect influenced by society. That is why that Indonesia. As a result, its central government has legalized the Regulation of Government 21, 2020, restricting society to limit their daily accessibility, such as studying at school, working at the office, and praying at the mosque. Referring to this regulation, education is a significant point that must be highlighted further in connecting to recently both its implementation and systems used by each educational institution. Based on United Nations' data in 2020, it is confirmed that there are over 191 countries that closed due to the COVID-19 situation; moreover, 1.5 billion students and 63 teachers or instructors in the levels of primary and secondary remain affected. The truth made satisfactory alter towards the education system in the world, and the advance of virtual mode existence supports it.

The expeditiously, irrefutable, and critical change from routine (offline learning to virtual learning) has to be executed, taking after won rules (Morrison \& Escobar, 2020, Bao 2020, \& Dhawan, 2020). A concept of routine shows the students' school activities typically

148 | IJET| Volume. 10, Issue 2. December 2021 Copyright 2021 Fifi Nur Ulwiyah, Ahmad Munir, and Slamet Setiawan are licensed under Creative Commons Atrribution-ShareAlike 4.0 International License. 
through the learning process instruction beginning from childhood up to a higher-level education. Ongoing online learning is not only successful for the fetched (Mc. Avoy, Ballagan, \& Baxter, 2008). Klomp (2020) also says that it helps the students enhance and strengthen their motivation to study. They also state that ongoing online learning allows students more without considering their zone and distinctive social status. Online learning is technologybased which its instruction and learning could be the elective method to attain the education programs and practices. This could be coordinated with plenty of online devices and resources (Flores \& Carillo, 2002). In this way, integrating technology and pedagogy practices is required in the language classroom.

Teachers may utilize a few articles, video recordings, podcasts, and websites within the additional materials - moreover, the stage links with the learning management system or LSM and web institution. For instance, the platform 'English Discoveries' is accessible for the higher students in one of the state Islamic universities in Surabaya, where different skills are taught. It is mainly controlled by the International Test Center (ITC) in learning English through hybrid learning (Maiden \& Smith, 2005). The students could join in the meeting and do the assignment online through the English platform provided. As confirmed by Thomas (2015), it is considered to balance things since discovering much resources and doing tasks from specific web or platform could give them a chance to develop themselves in learning the language.

In addition, adjusting online learning rouses teachers to select an appropriate material to fulfill students' needs and interface in teaching language. Huda (2007) adds it can create significant activities by involving authentic materials. The product of original materials is the urge to accomplish into the social environment where the language community is included (Peacock, 1997). It also brings the language context to the real world, so there should be a parallel between classroom activities and movements towards the real-world (Richard, 2006). As more the advanced of technology, a plenteous arrangement of online materials is openly picked up to help the online learning lesson. Furthermore, the point at providing many additional resources to students, the authentic reading materials are chosen in presenting the role of English, specifically, foreign language.

Within the zone of ESP (English for Specific Purposes), reading comprehension is utilized to prepare English for TOEIC as International Communication. There are four sections in the reading section: Reading Comprehension, Text Completion, and Incomplete Sentence, which is the required course for first-year students and taught in Intensive Course. Thus, the instructors' suitability of authentic material in the reading section has to cover the needed substance that reminds significant.

Some researchers have practically implemented resources by the instructors or teachers. Azam \& Omid (2016) are based on the language communicative for both reading and listening skills. Cavani's study (2007) revealed that reminders of natural resources or materials are crucial. However, in a few cases, teachers failed to define and implement the usage of these natural resources or materials. Furthermore, Anam et al. (2019) \& Huda (2017) show the teachers' positive attitude towards using the existing resources or materials provided. Yusuf \& Purwaningrum (2002) stated that the digitization of authentic materials has to catch up with the students' interest in learning English. To stimulate students in English language skills, the English teachers have to focus on the implementation of the authentic materials that can also be available in ESL or EFL for various settings. However, few studies aimed at the authenticity of online accurate reading materials used by the teachers. Therefore, this study investigates the authenticity used and teachers' challenges in implementing original online

149 | IJET| Volume. 10, Issue 2. December 2021

Copyright 2021 Fifi Nur Ulwiyah, Ahmad Munir, and Slamet Setiawan are licensed under Creative Commons Atrribution-ShareAlike 4.0 International License. 
reading materials in online reading classes.

\section{METHOD}

The design of the study used is a qualitative approach. Ary et al. (2010) reported that a case study provides a deep, rich and complete explanation through the investigation of its part or a single unit. The subjects of this study are three EFL teachers from higher education. During what is known as the Intensive English Course, teachers must teach first-year students General English and English for Specific Purposes for two semesters.

The selection of subjects is based on specific criteria. The first criterion is the experience of EFL teachers in using the Discover English platform since its launch and initial use. The second criterion is a TOEIC reading score of over 400. Next, these four EFL teachers apply virtual meetings using authentic documents, as teleconferencing applications also support them. Like Google Meet and Zoom Cloud Meeting. Later, they were part of the same intensive English language courses organization in several English centers. In addition, they have completed a master's program or pursued research. The basis of the study is the ELT online course at one of the particular State Islamic Universities in Surabaya.

The techniques of data collection are observation and interview. In this study, the ELT online class was selected as an observation, in which the author was the non-participating observer. It is important to note that the non-participating observer will have a concrete comment because the observer does not actively participate in natural phenomena and the actual conference experience in this class (Creswell, 2012). Writers also record observational data using field notes to record detailed information about events, people, and activities. In addition, Reflection Notes are also presented as the writer's personal opinions about the circumstances and places created by the subject. Meanwhile, the interview is conducted to seek the teachers' point of view related to the challenge they face in implementing authentic online reading materials in online reading classes. For data analysis, this study used Ary et al.'s (2010) theory: knowledge and organization; encryption and minification; interpreter and representative.

\section{RESULT}

The teachers used a blended reading class, in which he combined online teleconference (Google Meet) and online student tasks (Explore English) as a multi-learning platform. Important means. This learning focuses on students' performance by performing several functions provided individually through the online platform and discussed together in the classrooms.

\section{A. The Authenticity of Online Authentic Reading Materials Implemented in Online Reading Classes}

It is important to note that the authenticity of online reading materials is needed in teaching and learning in an online reading class conducted by teachers. The description of the authenticity of online authentic reading materials is discussed based on the three EFL teachers reading practices in the following details.

\section{The Authenticity of Online Authentic Reading Materials of T1}

T1 is the first EFL teacher observed through online observation to view the authenticity in using online authentic reading materials. During two meetings conducted, T1

150 | IJET| Volume. 10, Issue 2. December 2021

Copyright 2021 Fifi Nur Ulwiyah, Ahmad Munir, and Slamet Setiawan are licensed under Creative Commons Atrribution-ShareAlike 4.0 International License. 
continuously displayed the advertisement text as part of the original materials in the practice of reading skills which is the English language used as it is in accordance with Second Language Acquisition (SLA) influence for helping the students in acquiring a foreign language towards the input of language used in the advertisement. The advertisement content was 'U-Do Hobby Shop,' with a tagline of 'everything you need for your hobby.' T1, specifically, divided the text into three parts; brief information about a shop, more detailed information about the things provided, and its opening hours. Then, the influence of language pedagogy could be found through the communicative interaction created by the teacher with her students. In terms of Information Communication and Technology (ICT), T1 used Google Meet teleconference to teach reading. The advertisement text is authentic. However, she did not show the authenticity of its reading materials direct online. The advertisement text materials had been chucked into three parts in the form of an image, which was used to be displayed during her online reading class.

\section{The Authenticity of Online Authentic Reading Materials of T2}

T2 is the second EFL teacher that had been observed through online observation. In conducting two meetings, T2 shared Discoveries Magazine provided by the English Discoveries platform. The Discoveries Magazine contains many magazine themes such as sport, education, health, lifestyle, fashion, etc. A forum also distinguishes the English magazines based on three primary, advanced, and intermediate levels for the learner. Thus, it will be easy for the teacher to choose one of the themes and its level that is, of course, appropriate for the students. Due to the different contents and themes of English magazine offered, it supports Second Language Acquisition (SLA) influence in enriching students' vocabularies. In presenting authentic materials, there are two magazines chosen entitled 'Dream Home, Dream Price' for the first meeting and 'Social Distancing Gets Creative' for the second meeting. The second title of the magazine is preferred because it fits the nowadays pandemic situation of the Corona Virus. T2 used two languages, both English and Indonesian, to have smooth communication in teaching reading, as the language pedagogy shared in online reading class.

Regarding Information and Communication (ICT), T2 presented the authentic reading materials via Google Meet. The Discoveries Magazine is genuine. Further, the authenticity is also proven through how $\mathrm{T} 2$ presents the reading materials directly online by opening the English Discoveries platform during the class.

\section{The Authenticity of Online Authentic Reading Materials of T3}

T3 is the third EFL teacher that had been observed through online observation. Two meetings were conducted in which T3 used the English Discoveries platform by sharing one of the article passages from the unit provided. In dealing with SLA influence, the articles give more insight for the students and get the language input about social phenomena and common cases that occurred in society. Two article passages are displayed in two meetings entitled 'Does Homeless Mean Helpless' and 'Adam Murder Mystery Update.' The first article discussed one of the social phenomena problems, homeless people, in which T3 also connected it to a society live occurred in Indonesia. At the same time, the second article talked about a murder that sometimes a case can be found surrounding us. T3 had been motivated to speak English more by asking their opinion related to the topic of discussion and sharing the difficulty in understanding some unknown words. In this case, the language pedagogy used is English and Indonesia to communicate actively among teachers and the students. The last ICT

151 | IJET| Volume. 10, Issue 2. December 2021 
influence is shown in how T3 presented the authentic reading materials using Google Meet. The materials are authentic because T3 took them from the English Discoveries Platform with various theme, and of course, it links to the real-world situation and phenomenon. The other authenticity can be proven by which $\mathrm{T} 3$ shared the materials directly online and gave additional information about the thing related to text by browsing it via Google aid.

In learning English, authenticity is considered pivotal since, in this case, English is taught as a foreign language, not as the first language or second language that does not much need its authentic materials to be shared. The original materials can be said its prevalence by measuring each authenticity based on three areas. These influences are coined by Mishan (2005), which are SLA (Second Language Acquisition), language pedagogy, and ICT (Information and Communication Technology).

First, acquiring language in the context of the second language views how the authentic texts have a significant impact on the students. The input can see this influence of language used in the advertisement, the enrichment of students' vocabularies, and the language input about social phenomena and common cases in a society exhibited by those three EFL teachers. Instead of SLA, the language pedagogy stands for its communicative and smooth interaction by using both English and Indonesian language in teaching online reading done between teachers and students.

Furthermore, the completeness of online authentic reading material does not remind meaningfully without any authenticity term viewing from Information Communication and Technology (ICT) influence. It means that the teachers have to display the real authentic materials via direct online medium or synchronous) learning (Martina and Oyarzun, 2017), such as by opening the English Discoveries platform and providing the additional information or materials using Google. Thus, these three areas could establish the applied authenticity to the language learning design materials, especially English.

\section{B. The Teachers Challenges in Implementing Online Authentic Reading Materials in Online Reading Classes}

The interviewees identified several points made by the three EFL teachers when describing the difficulty EFL teachers face when implementing authentic online materials in reading activities to ascertain teachers' knowledge and comprehension regarding the integration of reading skills practice. There are some points gained from the teachers, including the knowledge about authentic materials, the use of online authentic reading materials, the way to integrate online authentic reading materials into English lessons, problems and challenges faced, and the way to solve the problem in implementing those materials.

The teachers' knowledge about authentic materials includes three points of view. All teachers understood the concept of authentic materials and gave it a simple definition. T1 said, "Authentic material is real material from the target language that the teacher used to engage students. For instance, English magazine, English song, English game, English novel, etc." It is in line with T2's opinion, "Authentic materials are learning materials sourced from a reallife condition such as newspaper, magazines, novel, instructions, etc." While T3 said that "Authentic materials sourced based on its original contexts, such as articles or news taken from online BBC and VOA." Based on their statement, it is believed that most EFL teachers truly know the sources used for teaching English as well T1 and T2 shared the same things.

152 | IJET| Volume. 10, Issue 2. December 2021

Copyright 2021 Fifi Nur Ulwiyah, Ahmad Munir, and Slamet Setiawan are licensed under Creative Commons Atrribution-ShareAlike 4.0 International License. 
However, T3 only focuses on the online text sources taken from online BBC and VoA in which the English language is used for each particular topic written by the authors.

Moreover, the teachers agreed that using online authentic reading materials could be much beneficial for the students. T1 said, "It was beneficial in using the authentic materials because it could help the students to involve in the real English atmosphere. They also could have more experience in using authentic reading material." So that the students would not be amazed when they had to face the real-world supplement materials, then, "The use of authentic materials that represent real-life context is significantly beneficial for students, " as added by $\mathrm{T} 2$.

The other responses answered by T3, she said, "I think it is great if the students are motivated to read a lot of English books from the original sources because the students are accustomed to reading any texts in the working field after graduating. Besides, it can help them use the simple English language, not the English language that is forced from Indonesian language translation. The English that does not sound natural." Her statement emphasizes that the students or the learners are better at learning English from the sources in increasing their reading skills.

To integrate online authentic reading materials, some ways are utilized in the online reading classes. T1 used online reading material provided by the platform in her institution where she is taught. The platform is called English Discoveries. "I discussed what students had read at home, and she talked about the lesson inside the reading. Even we talked about the culture if we found it in reading", T1 said. She attempted to conduct an intense discussion of culture within the learning process. Another teacher, T2, also employed English Discoveries because it provided authentic materials, including the listening and reading materials section. T2 also added, "Thus, he found it easy to use the materials without looking for external sources."

In contrast, T3 confirmed that the authentic materials used are based on a learning theme. So that the students can obtain much vocabulary from the reading passage, it can be said that T3 focuses on students' vocabulary input to help them understand many contexts in reading. Both $\mathrm{T} 2$ and $\mathrm{T} 3$ also conducted reading together, finding out the new vocabulary and determining the main idea from those texts.

However, teachers also got a challenge in implementing this online authentic reading material in their teaching online. As it was revealed by $\mathrm{T} 1$, "The challenge was that the students didn't remember what that read independently. Then, it caused some problems, such as the discussion becoming longer because they had to explain the reading first. Then, it took practice time." Since the classroom activities were conducted online, the students were not focused during the reading practice and ended up getting bored.

The different challenges faced by $\mathrm{T} 2$ about the difficulty of materials provided by English Discoveries. He said, "Sometimes, the topics are beyond the reach of Indonesian students. The topics are snow, foreign culture, vintage technology, etc." Another challenge is about students' habitual reading. As T3 commented, "Habitual reading activity should be built, especially for a basic level of English language. The challenge is to choose a suitable article to the student's level of English." Here, the point is that the students have to upgrade their knowledge through habitual reading action due to its fit to their ability in conquering the English language based on their level.

In overcoming the challenge and the problem, each teacher implements different strategies. T1, for example, reminded the students to read and take note of the theme, complex words, and some points in the reading. It is needed to highlight the critical issues found during

153 | IJET| Volume. 10, Issue 2. December 2021 Copyright 2021 Fifi Nur Ulwiyah, Ahmad Munir, and Slamet Setiawan are licensed under Creative Commons Atrribution-ShareAlike 4.0 International License. 
the reading activity. In other ways, T2 must do direct improvisation and adaptation to unrelated authentic materials. He confirmed, "Frequently, I need to provide a deep explanation to make my students can relate to the discussed authentic material topics." Creating connections and sharing connections are strategies that can be implemented to deal with this opinion.

Additionally, T3 gave clues about the point delivered in the articles and triggered the students by providing some questions based on the paper they read. "If they are interested, then they will be motivated to learn more, " added T3. Overall, they also attempted to modify the reading materials to match the natural world and add the variation of activities to have more idea regarding the text discussed. Therefore, implementing various authentic reading materials online reminds pivotal for developing students' knowledge, especially in upgrading their reading skills.

After conducting the interview, the researcher some points related to the implementation of online authentic reading materials. First of all, the three teachers understood the concept of the original materials and gave a simple definition. The teachers agreed that using online authentic reading materials could be much beneficial for the students to know the real world. Therefore, it needs to integrate original online reading materials using ways such as providing English platforms from teachers' institutions.

However, it also discovered that most teachers got challenged in implementing this online authentic reading material. The first challenge was that the students didn't remember the content they read, which made the discussion longer because they had to explain the reading first. Since the class was conducted online, the students were not focused during the reading practice and got bored. Pasaribu (2020) suggests practicing the online tasks in a reading course in which he used digital reader response in a Moodle-based. This activity engages the learners in learning an expressive language and nurtures their autonomy dimensions. Next, the challenge is about the difficulty of materials provided by English Discoveries. Regarding students' habitual reading, the challenge is to choose a suitable article to the student's level of English.

Therefore, some suggestions are coined by Candy and Taylor (2006) to avoid the challenge. It is included the four questions that teachers can use as the guidelines in creating or providing authentic materials for EFL students. The questions are: (1) Are the authentic materials appropriate for the student's proficiency level? (2) How appropriate are the authentic materials and their activities towards students' age and maturity? (3) Are the authentic materials provided relevant to students' interests? and (4) What vocabulary words need to be introduced and pre-teach before instructing the students to read the authentic materials.

\section{CONCLUSION}

Throughout the qualitative approach, this study is aimed to examine the authenticity of online authentic reading materials, how teachers implement online accurate reading materials in teaching English as a foreign language, and what are challenges faced by teachers in the process of teaching and learning. Original reading material is, expanding more sources and references of reading passages that connect between the classroom and the real world. In delivering this abundance of materials, specifically, it is needed to see how the EFL teachers perform reading comprehension strategies to build the connections in the sequences of prereading, during reading, and pra-reading in the online reading classes.

The authentic materials can be said its prevalence by measuring each authenticity based

154 | IJET| Volume. 10, Issue 2. December 2021

Copyright 2021 Fifi Nur Ulwiyah, Ahmad Munir, and Slamet Setiawan are licensed under Creative Commons Atrribution-ShareAlike 4.0 International License. 
on three areas, including SLA (Second Language Acquisition), language pedagogy, and ICT (Information and Communication Technology). It could establish the applied authenticity to the language learning design materials, especially learning the English language.

In this case, the reading supplements cover advertisement text, online magazines, and articles text. To deal with this, some common strategies such as activating knowledge (schemata), questioning, and determining ideas are more frequently used, integrated, and developed within other relevant procedures. Teachers are supposed to create the positive situations as well as have the creative and various learning activities and ways due to the classroom is conducted via online. Inserting the parts of culture, that is, social life, social phenomena and society habits becomes the most exciting sharing to enrich students' knowledge and open their more expansive thinking about the idea of language and culture. All in all, it is taken into consideration that reading comprehension strategies can implement online authentic reading materials practices.

Referring to the results presented, several suggestions were made by the researcher. First, the final results of this study can be used as an additional benchmark for subsequent researchers to consider focusing on authentic online materials and strategies for using the reading comprehension ability. EFL teachers may incorporate other strategies, materials, or resources to support reading improvement activities. Since the session was conducted online, it was possible to transform the material into a short and varied practice using various authentic reading sources. In addition, original materials become a window into bridging the gap between classroom learning and the real world. So it would be nice to have the suitable material to share and discuss further.

\section{REFERENCES}

(2020, April 01). Retrieved November 21, 2020, from https://setkab.go.id/en/presidentjokowi-signs-govt-regulation-on-large-scale-social-restrictions/.

(2020, April 21). Retrieved November 24, 2020, from the United Nations: https://news.un.org/en/story/2020/04/1062232.

Anam, K., Munir, A., Anam, S. (2019). Teachers' Perception about Authentic Materials and Their Implementation in the Classroom. IJET, Vol. 8, Issue 1, June 2019, pp.1-9.

Ary et.al. (2010). Introduction to Research in Education. Eight Edition. United States: Wadsworth Cengage Learning.

Bao, W. (2020). COVID-19 and online teaching in higher education: A case study of Peking University. Hum Behav \& Emerg Tech. Vol. 2, 113-115.

Baxter, J., Callaghan, G. and McAvoy, J. (2018). The Context of Online Learning: Neoliberalism, Marketization and Online Learning. In Baxter, J., Callaghan, G. and McAvoy, J. Creativity and Critique in Online Learning. Exploring and Examining Innovations in Online Pedagogy. UK: Palgrave Macmillan.

Carrillo, C. and Flores, M. A. (2020). COVID-19 and teacher education: a literature review online teaching and learning practices. European Journal of Teacher Education, 43:4, 466-487.

Creswell, J.W. (2012). Educational Research. Planning, Conducting, and Evaluating Qualitative and Qualitative Research. Fourth Edition.

Dhawan, S. (2020). Online Learning: A Panacea in the Time of COVID-19 Crisis. Journal of Educational Technology Systems, Vol. 49 (1) , 5-22.

Fauzia, S. (2019). A Descriptive Analysis of Students' Difficulties in Comprehending English

155 | IJET| Volume. 10, Issue 2. December 2021 Copyright 2021 Fifi Nur Ulwiyah, Ahmad Munir, and Slamet Setiawan are licensed under Creative Commons Atrribution-ShareAlike 4.0 International License. 
Reading Text. Thesis. Unpublished Paper: IAIN Salatiga.

Huan, N. B. and Ngan, N.T.K. (2017). Summarizing Strategy: Potential Tool to Promote English as a Foreign Language (EFL) Students' Reading Comprehension in a Vocational School, Vietnam. European Journal of Education Studies. Vol. 3. Issue 8. 51-72.

Huda, M. (2017). The Use of Authentic Materials in Teaching English: Indonesia Teachers' Perspective in EFL Classes. PEOPLE: International Journal of Social Sciences, 3 (2), 1907-1927.

Irawati, I. (2019). Use of Questioning Strategy to Facilitate Students' Reading Comprehensio in Taiwan. Journal of English as a Foreign Language. Vol.9, No.2. 217-230.

Kispal, A. (2008). Effective Teaching of Inference Skills for Reading. Literature Review. National Foundation for Educational Research. UK: The Department for Children, Schools and Families.

Klomp, N. (2020, May 28). Retrieved November 21, 2020, from The Jakarta Post.com: https://www.thejakartapost.com/academia/2020/05/28/how-covid-19-will-transformaccess-to-education.html

Martin, F. and Oyarzun, B. (2017). Distance Learning. In West, R.E. Foundations of Learning and Instructional Design Technology. The Past, Present, and Future of Learning and Instructional Design Technology. EdTech Books.

Mishan, F. (2005). Designing Authenticity into Language Learning Materials. UK: Intellect Ltd.

Nobles, L.M.A.G and Ortega-DelaCruz, R.A. (2020). Making Connections: A Metacognitive Teaching Strategy in Enhancing Students' Reading Comprehension. Journal of English Education. 5(1):49-60. DOI:10.31327/jee.v5i1.1209.

Nobles, L.M.A.G and Ortega-DelaCruz, R.A. (2020). Making Connections: A Metacognitive Teaching Strategy in Enhancing Students' Reading Comprehension. Journal of English Education. 5(1):49-60. DOI:10.31327/jee.v5i1.1209.

Peacock, M. (1997). The Effect of Authentic Materials on The Motivation of EFL Learners. English Language Teaching Journal, 51. January 9, 2021 from https://busyteacher.or/16195-reading-material-8-best-authentic-sources.html.

Purwaningrum, A.Y. and Yusuf, F.N. (2020). Investigating Digitized Authentic Materials: PreService Teachers' Voice. Edulite Journal of English Education, Literature, and Culture. Vol. 5, No. 2, August 2020, pp. 225-239.

Rahadhiyanti, dkk. (2016). Authentic Reading Materials from Internet to Enhance the Eight Grade Students' Reading Comprehension. EFL Education Journal. Vol. 3, No. 8. pp. 573584.

Rao, P. S. (2020). The Use of Authentic Materials as Motivational Tool in The ESL or EFL Classrooms. Academicia. An International Multidisciplinary Research Journal Vol. 10, Issue 2, February 2020, pp. 7-18.

Richard, J.C. (2006). Communicative Language Teaching Today. New York: Cambridge University Press.

Sepulveda-Escobar, P. and Morrison, A. (2020). Online teaching placement during the COVID-19 pandemic in Chile: challenges and opportunities. European Journal of Teacher Education, 43:4, 587-607.

Shank, P. and Sitze, A. (2004). Making Sense of Online Learning. A Guide for Beginners and the Truly Skeptical. San Francisco: Preiffer A Willey Imprint.

Soufiane, T. (2016). Authenticity in Materials Development in Issues in Materials Development. Critical New Literacies. M. Azarnoosh et.al. (Eds.). Boston: Sense

156 | IJET| Volume. 10, Issue 2. December 2021 Copyright 2021 Fifi Nur Ulwiyah, Ahmad Munir, and Slamet Setiawan are licensed under Creative Commons Atrribution-ShareAlike 4.0 International License. 
Publishers.

Wahyuni, F. and Jufri. (2016). Using Making Connections Strategy in Teaching Reading Comprehension at Senior High School. Journal of English Language Teaching. Vol.5.No.1.1 Serie C. 175-183.

Yavani, Z. (2017). Authentic Materials: Teachers' Perception and Why It is Matters. ELT-Echo, volume 2, number 1, June 2017, 26-36. 